\title{
El divismo en tiempos de \#Instagram
}

\author{
Maria Michela MatTEI \\ Grupo de Estudios de Semiótica de la Cultura (GESC) \\ Traducción de Alessandro Gianetti
}

(Abstracts y palabras clave al final del artículo)

Propuesto: 15 de octubre de 2014

Aceptado: 16 de octubre de 2014

La semiosfera mediática contemporánea se perfila como una explosión de aquel iconic turn que nació hace veinte años en respuesta a la invasión panlingüística según la cual todo producto cultural y toda cuestión epistemológica podrían ser reconducidos a una cuestión de lenguaje. En la época de Internet, de la telefonía móvil y de los content on demand, las imágenes son ya parte de nuestra vida, con una cantidad y su abundancia y frecuencia tales que penetran nuestras formas de conocimiento y de aprendizaje, para llegar a nuestras pantallas como ríos ensanchados sin mediación aparente. Lo visual proporciona cada vez más sentido y forma a nuestro mundo, con su bagaje testimonial e inmediatez icónica; las imágenes de la crónica pueblan los telediarios y la prensa junto a la continua espectacularización de la realidad. ¿Pero de verdad es así? ¿A una mayor cantidad de imágenes, documentos audiovisuales y ramificaciones intertextuales corresponden de verdad un mayor conocimiento y una mayor comprensión de la realidad?

En la semiosfera contemporánea las barreras tecnológicas, económicas y teóricas entre emisor y receptor han derivado en las potencialidades de las redes, así que a esta proliferación de imágenes corresponde también una redistribución de las tradicionales formas de espectatorialidad, donde ya no se distingue entre un espacio de observación y un espacio performativo, sino que se concentra todo en un único público performer. Emerge de estas rápidas observaciones la nueva dimensión cultural de la imagen como objeto construido en lo social, además de variable en lo histórico: la discontinuidad reside en el hecho de que hoy la potencia de lo visual, su capacidad de fascinación, se encuentra diluida en una liquidez postmoderna que nivela lo alto y lo bajo y hace posible la convivencia entre diferentes registros, gracias a la omnipotencia de la plataforma de las redes. Si ya no existen jerarquías, el icono tiene que investigar otras formas de narración y de representación, no solo para volver a ejercer su poder sobre un público observador, cada vez más atento e informado, sino también para fortalecer aquella ilusoria naturaleza de referencia que le caracteriza. El icono ha sido destronado, obligado a bajarse del pedestal y a mezclarse con las otras imágenes, negociando continuamente su propio sentido. La 
muerte del icono ha coincidido con su multiplicación en dobles simulacros, todos igualmente válidos y auténticos, y hoy solo puede volver a emerger a través de una nueva mediación y montaje de fragmentos, en un incesante proceso de transformación. El tema es, una vez más, el poder de las imágenes en un campo de fuerzas de doble dirección: la dirección centrífuga del icono imagen visible, que reenvía continuamente a algo diferente de si mismo, y la dirección centrípeta del ídolo aglutinador, que requiere veneración, suscita pasiones y que no acepta, en su calidad de imagen revelada, la comparación ni la selección paradigmática entre otros textos.

Un campo de investigación especialmente interesante para explorar los cambios en la semiosfera mediática es el divismo: un fenómeno capaz de evocar tanto el plano sagrado/vertical del icono como el pagano/horizontal del ídolo. Lo que se yergue en la nueva semiosfera contemporánea, en definitiva, es un nuevo panteón profano, distante y a la vez cercano, dominado por la celebrity: estela astral de lo que un tiempo atrás fue la estrella del Olimpo teatral y cinematográfico y que ahora aparece como fragmentada en un enjambre de millares de imágenes tomadas, filtradas y compartidas. El carácter mítico-religioso del ídolo profano y del icono sagrado - que mantenía en el divo tradicional sólidas huellas de una coherencia iconográfica y narrativa - se reduce a fetiche digital cuya fascinación resulta dispersa y ubicua en la proliferación iconográfica de la celebrity postmoderna. La distancia astral que aseguraba el mecanismo de proyección e identificación entre el divo y su público, está hoy aparentemente cancelada por la ilusión de proximidad de los medios de comunicación. Si antes la imagen de la estrella se tenía cerca a modo de carte de visite, hoy el contacto es mediático y multiplicado por los personal devices, móviles y similares, que actúan como multiplicadores de imágenes a través de las redes sociales: Instagram y Twitter en primer lugar. El resultado es una carrera hacia la saturación de las imágenes del divo, que ofrece continuamente instantes de su propia vida al público potencialmente ilimitado de la red, hasta llegar a las formas más íntimas e inmediatas del selfie.

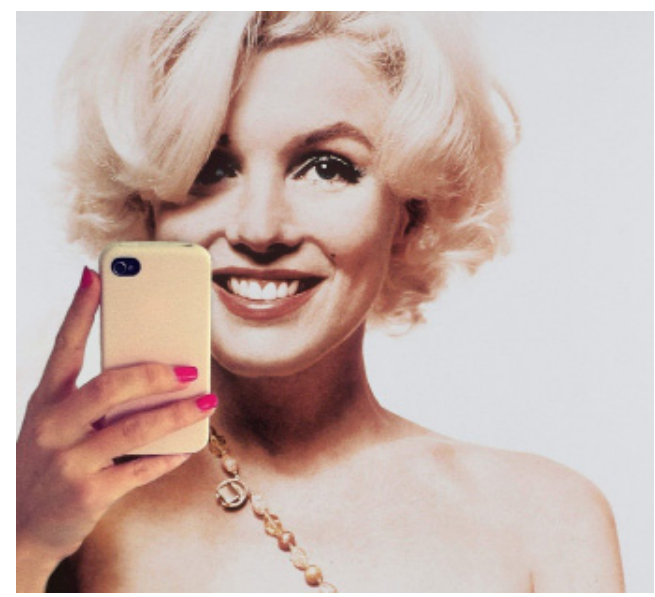

Fig.1. Marylin Monroe en un selfie (montaje fotográfico). 
Ya a partir de estas primeras notas se deduce que el divismo se presenta como un fenómeno de profundo interés para la semiótica visual, construido sobre parejas de oposiciones como las de público/privado, notoriedad/anonimato y sobre todo ser/aparentar, que en un contexto visual es declinable según la dicotomía secreto/transparencia. Esta estrategia vinculada al régimen de lo visible está en la base del mecanismo de representación del divismo desde sus primeras manifestaciones, que se remontan a finales del siglo XIX; es más, este juego de ofrecerse y esconderse a los ojos del público es precisamente el "truco" mediático de la celebridad: suministrar con tiempos y maneras debidamente estudiados fragmentos del ser, ilusiones de proximidad, atrayendo sin nunca conceder una real ocasión de encuentro, de posesión o de simple contacto y delegando dicha posibilidad al doble simulacral: la imagen, la reliquia que es también la fuerza de la naturaleza indical del divo.

Este artículo se propone analizar el paso de Divo a Celebrity, a través de la construcción de un icono mediático que desde la Modernidad se traslada a la Postmodernidad y hacia una nueva iconografía del divo, con nuevas estrategias de enunciación reguladas por las redes sociales. Instagram, en particular, es la red social que mejor se caracteriza como campo de observación para explorar estas nuevas formas de representación y estrategias persuasivas. En efecto, si por un lado el fenómeno se ubica en una línea de continuidad con los rasgos tradicionales del divismo (sobre todo por la centralidad de la imagen, pues es con la fotografía que nace la posibilidad de construir mediáticamente un mito) por otro es verdad que la tendencia se dirige hacia una iconografía con fuertes discontinuidades con respecto al pasado, caracterizada por un desplazamiento hacia la transparencia y la proximidad al receptor.

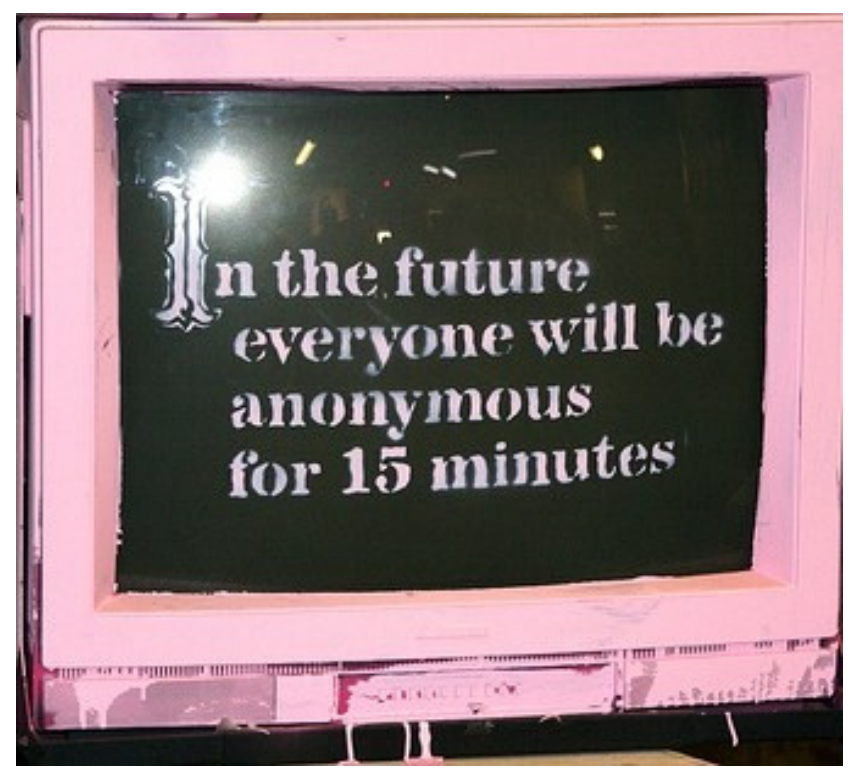

Fig. 2. Banksy, instalación. 
La provocativa instalación de Banksy (el célebre grafitero británico que debe su popularidad a la fuerza de sus obras y a la estrategia de misterio que rodea su personalidad $^{1}$ ) nos lleva al cambio de paradigma que vivimos tanto en el ámbito social como en el comunicativo: un cambio polarizado en la pareja secreto/transparencia que no atañe solo la información, sino también a la identidad de las personas, como claramente demuestran el éxito de las redes sociales y la sistemática mise en scène de nuestra cotidianidad. Este cambio en la esfera mediática está vinculado a la convergencia entre espectáculo, marketing y sociedad, hacia un efecto maquillaje que lleva a una presentación estética más o menos consciente de cualquier tipo de producto, incluida la identidad, convirtiendo cualquier gesto comunicativo en un ejercicio de estilo antes que de sustancia. Una tendencia tempranamente relevada y teorizada por los Audience Studies, que definen al público contemporáneo en términos de diffused audience (después de la era del simple audience y del mass audience) y público performer, en el que se esfuma la distinción entre productores y consumidores de cultura.

La tendencia a la performance y por tanto a la visibilidad del diffused audience derivan de dos procesos: por un lado la construcción del mundo como espectáculo y, por otro, la construcción de los individuos narcisistas. Espectáculo y narcisismo se alimentan recíprocamente en un circuito generado por los medios de comunicación y por el desarrollo de las competencias mediales del público, que tenderá a una mirada cada vez más espectacular sobre el mundo (Sfardini 2009: 49, traducción nuestra).

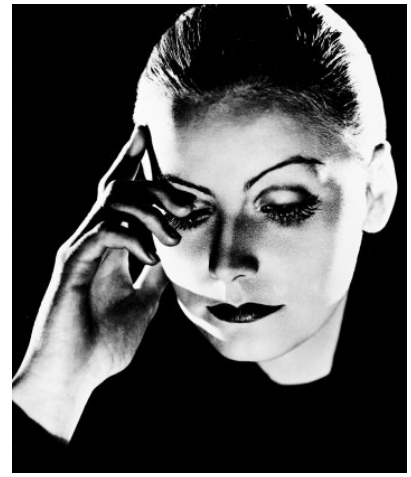

Fig. 3. Greta Garbo: la iconografía de la diva.

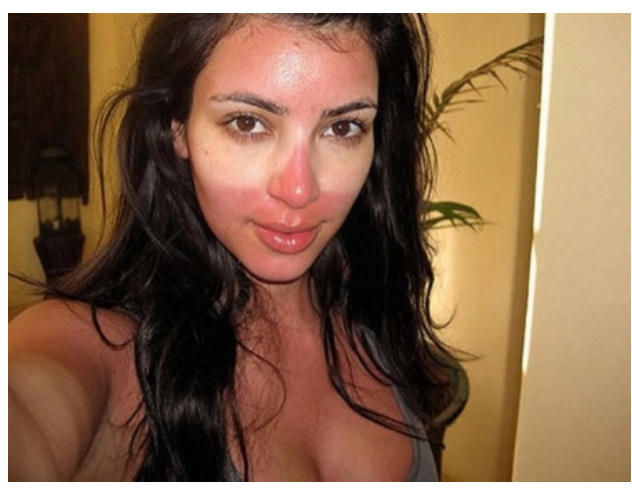

Fig. 4. Kim Kardashian: Selfie.

1 "I don't know why people are so keen to put the details of their private life in public. They forget that invisibility is a superpower". Declaración de Bansky: http://www.theawsc.com/2013/08/08/when-andy-metbanksy/\#ibCOtcozhQFXldsY.99 
La comparación entre las imágenes de Greta Garbo y de Kim Kardashian muestra, con la claridad típica del registro visual, la distancia que separa la iconografía de la diva tradicional de la iconografia de la celebrity. Por un lado tenemos la imagen intransitiva extrema, la opacidad y el misterio (el uso del blanco y negro, la pose reflexiva, la mirada alejada) y, por el otro, la transparencia y la transitividad extrema (la mirada dirigida hacia la cámara, la ausencia de maquillaje y el selfie). Las dos imágenes no representan solo dos iconos opuestos, sino también dos extremos desde el punto de vista teórico: Greta Garbo se coloca entre el ámbito de la tradicional definición de Morin del divo cinematográfico como mito de la modernidad, "revisión del culto clásico griego-latino, personajes de la narración épica que ejercen sobre el público un doble mecanismo de proyección e identificación" (Morin, 1962); Kardashian, por el contrario, es la celebrity contemporánea que se puede permitir ofrecer una imagen humana, demasiado humana, como resultado de una exitosa autopromoción construida a través de los mecanismos de la red.

¿Qué ha cambiado entre estos dos extremos? La definición de divo de Morin está firmemente anclada en el sistema de los divos hollywoodienses, basado a su vez en el poder de los Studios ${ }^{2}$, que se empieza a resquebrajar a partir de los años sesenta. A partir de ese momento las grandes casas de producción ya no disponen de los derechos de imagen de las estrellas, ni se encuentran en posición de "protegerlas" del sistema mediático que empieza a destruir esa coincidencia entre "persona" y "personaje" que los había escondido (salvaguardando sus vidas privadas gracias a la transparencia patinada de las imágenes oficiales). Para comprender los cambios que se están produciendo tenemos que empezar por el análisis de la proliferación iconográfica que se ha producido en los medios de comunicación a partir de la segunda mitad de los años veinte. Richard Dyer, allá por los setenta, reinterpretó la tradición teórica francesa sobre el divismo y lo efímero a la luz de una concepción de la star como sistema complejo, que se puede analizar a partir de la descomposición de su naturaleza iconográfica y visual ${ }^{3}$. Por un lado la imagen de la película (el actor entendido como encargado del papel temático), y, por otro, la imagen mediática (el divo/persona o mejor el actor entendido como actante de la estructura del cuento). Son dos estructuras narrativas bien diferentes: el personaje interpretado y la "máscara", con sus características estables y reconocibles: dos estructuras narrativas que, cuando coinciden, producen ese efecto de realidad que lleva al divo al máximo grado de popularidad. Se intuye pues que la definición de divismo no puede ya agotarse en la definición mítico-protectora que dio Morin (el star system hollywoodiense como una especie de Panteón profano), sino que pone el fenómeno en el horizonte más amplio de la representación y del moderno debate acerca del icono. Esta proliferación de imágenes —que los Estudios, que actuaban de acuerdo con los medios de comunicación, ya no pueden controlar - fundamenta el paso del divo a la celebrity. El primer término indica la celebri-

2 La mayor fascinación de este tipo de cine se debe a su aspecto onírico, a la inconsistencia realista de los personajes, a la alteridad del mundo en el que se desarrollan sus historias, bajo el lema del erotismo y de la muerte, contrapuesto a la monotonía de la cotidianidad. Es esta distancia que hace gloriosa la realidad representada en la pantalla, y que aclara cómo este género de producciones consagra fortunas divísticas de actores y actrices que, por primera vez en la historia del cine, adquieren una potente función simbólica que va más allá de los múltiples papeles interpretados. C.Jandelli, Breve storia del divismo cinematografico, Venezia: Marsilio, 2007.

3 R.Dyer, Stars, British Film Institute, 1979 
dad como efecto colateral de ser una estrella: el divo es lo que es gracias a una especificidad, una unicidad amplificada por la distancia impuesta por la pantalla; la celebrity, por lo contrario, legitima su status en el plano más inmanente de la popularidad, gracias a la cual puede definirse a sí misma como diva. La distancia vertical entre bajo y alto se traslada a una dimensión horizontal, en la cual predomina la difusión capilar de la imagen. Se trata de una verdadera inversión del sentido, un cortocircuito entre causa y efecto: el fenómeno tautológico del famous for being famous. Ser famosos ya no es una consecuencia, un efecto colateral debido a la unicidad del divo, sino una conditio sine qua non para ser definido como tal. El divo actual ya no es un héroe moderno con competencias adquiridas durante aquella narración tantas veces alimentada por las biografias hollywoodienses (la belleza de Rodolfo Valentino, el sofisticado atractivo de Audrey Hepburn o la carga erótica de Marilyn Monroe) y, sobre todo, no lo es en virtud de un complejo aparato de construcción y legitimación de la notoriedad conseguida a través del uso calculado de la imagen y de la representación de la estrella; el divo actual se lo debe todo a la popularidad cuantitativa que resulta del número de visualizaciones, de tweets y de likes que les proporciona la comunidad de seguidores. Se trata en buena medida de lo que Neal Gabler definió como Zsa Zsa Gabor effect $t^{4}$ : lo que de verdad define la celebridad actual es el "human entertainment", es decir la capacidad de entretener al público a través de su vida cotidiana: "a person who provides entertainment by the very process of living". Se va dibujando de este modo un nuevo Olimpo mediático que para emerger tiene que conocer a la perfección las reglas del juego y manejar herramientas y técnicas informáticas (gestión del entorno web, reputación digital etc..) y una estrategia narrativa capaz de aprovechar al máximo la enorme caja de resonancia representada por las redes a través de la búsqueda del escándalo y del disvalor social, según esa mezcla de inocencia, erotismo y peligrosidad típica tanto de la It-girl como del paradigma narrativo "good girl gone bad" (desde Kate Moss hasta Miley Cyrus) finalmente inmortalizada por una iconografía de fuerte impacto al estilo de Terry Richardson.
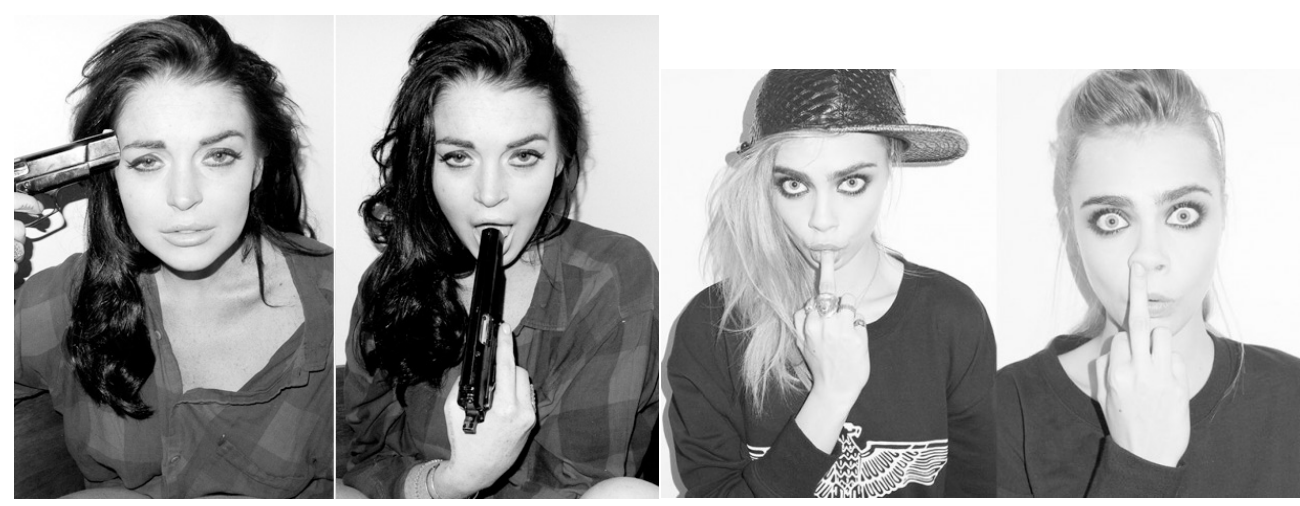

Fig. 5. Lindsay Lohan y Cara Delevigne fotografiadas por Terry Richardson.

4 http://www.randomhouse.com/boldtype/1298/gabler/interview.html 
El cambio no se ha producido, sin embargo, solo por el lado de los divos. También ha cambiado radicalmente el sujeto destinatario, el verdadero autor de la legitimación: el público. En el pacto comunicativo, la relación entre estos dos polos ha sido modificada hasta el punto que se atribuye al espectador el papel de protagonista del espectáculo de la realidad escenificado antes por la televisión y, ahora, por el reality show y las herramientas de Internet. Si la colectividad no se limita a proclamar y a legitimar la celebridad, sino que puede alcanzarla ella misma, es evidente que el mecanismo de proyección/identificación teorizado por Morin está destinado, de alguna manera, a la implosión. Ese sistema ha resistido mientras ha estado alimentado por el imaginario y el deseo vehiculado por imágenes patinadas, fotografias posadas y representación cinematográfica; en otras palabras, mientras ha existido una distancia. Hoy en día las nuevas tecnologías operan al contrario sobre la proximidad de la imagen del divo, empujando hacia la identificación y la esperanza que ese éxito pueda recaer en las manos de quien observa (it could happen to you). Las anteriores barreras económicas y tecnológicas también han caído: hoy somos todos potenciales editores de contenidos, productores y broadcasters, y podemos entrar en el sistema mediático con relativa facilidad. ¿Qué es entonces lo que sigue marcando la diferencia? Una vez más, la narración, el cuento ganador que atrae al público: contar una historia que tenga un entertainment value y un drama, es decir una parte humano/identificativa y otra mítico/proyectiva que será amplificada (retuiteada, publicada, compartida) por la enorme caja de resonancia de la red. Una historia que ya no es épica, sino cotidiana, o mejor dicho capaz de proyectar pequeñas epifanías de épica en la cotidianidad: fragmentos de un discurso amoroso, que diría Barthes, capaces de activar el antiguo y potente mecanismo de proyección e identificación: al álbum de familia se convierte de esta manera en el gran mosaico colectivo de Instagram, y el amor, el sentimiento más íntimo, en el hashtag (\#love) de mayor éxito.

A la luz de lo que hemos dicho, el divismo en los tiempos de Instagram puede considerarse como el resultado de dos tendencias convergentes, aunque aparentemente contradictorias: la transformación del mass medium en personal medium y el paso de unos medios de comunicación monodireccionales a bidireccionales. Culto a la personalidad y aumento del individualismo estetizante conviven con la actual democratización de la construcción mediática del sentido, con la posibilidad de intervenir directamente en la construcción de los contenidos y de comentarlos. ¿Pero cómo se ha producido a nivel visual y discursivo esta transición del divo clásico a la celebrity? Volvamos a las imágenes de Greta Garbo y de Kim Kardashian que hemos visto al principio: por un lado la coherencia de la imagen de la diva (coincidencia entre los atributos del personaje en la pantalla y los de las apariciones públicas de la persona/star) antes gestionada por los Estudios, y por otro la aparente transparencia de la celebrity que, ignorando todas la mediaciones posibles, se expone a sus seguidores en un selfie sin maquillaje y con los efectos de una quemadura solar. Hoy la comunicación interactiva permite una intercambio continuo entre la "diva/celebrity" y el "publico/followers". Es más, la interacción se ha convertido de facto en el instrumento o escamotage a través del cual los fans entran en contacto con sus personajes favoritos y reciben una especie de ilusión de cercanía. Como escribe Vanni Codeluppi, hoy somos "todos divos" y la tendencia conduce hacia una continua 
exhibición y autorepresentación hasta culminar en el selfie, una forma de presentarse estrictamente conectada al uso de las redes sociales. Esta es la definición que da el Urban Dictionary:

A picture taken of yourself that is planned to be uploaded to Facebook, Myspace or any other sort of social networking website. You can usually see the person's arm holding out the camera in which case you can clearly tell that this person does not have any friends to take pictures of them so they resort to Myspace to find internet friends and post pictures of themselves, taken by themselves. A selfie is usually accompanied by a kissy face or the individual looking in a direction that is not towards the camera.

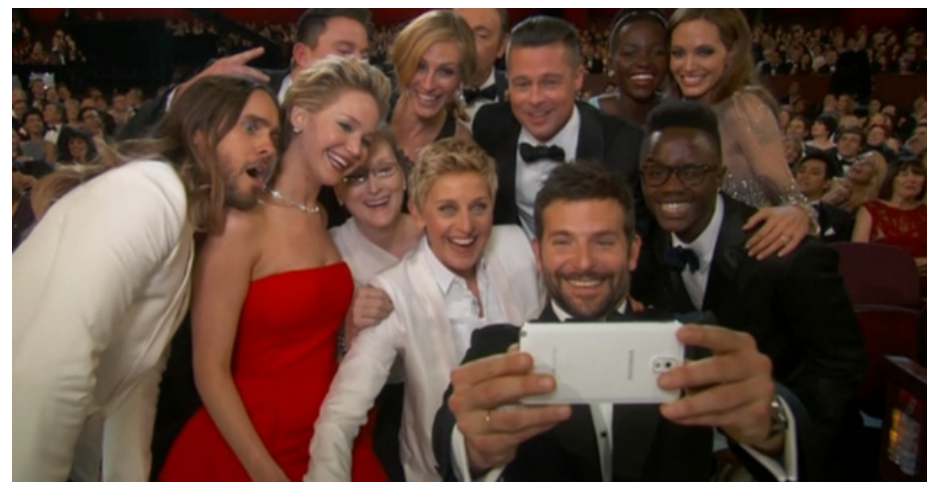

Fig. 6. Selfie de los divos de Hollywood en la noche de los Oscar 2014.

¿Estamos acaso asistiendo al final de la mediación? ¿Es el selfie un síntoma de transparencia y de democratización, una forma de mantener el control sobre la imagen de uno mismo, o es por lo contrario la última extensión del narcisismo desenfrenado de Andy Warhol? Naturalmente no existe una respuesta unívoca, porque toda definición lleva en sí misma su propia contradicción, y es precisamente en su naturaleza polisémica donde reside el interés hacia el selfie como figura y modalidad de representación contemporánea del divismo.

¿Pero cuál es la historia que queremos contar, y con qué medios? En el presente análisis estudiaremos un canal en particular, un medio que forma parte de la familia de las redes sociales aunque tenga características propias: Instagram, que se basa en la imagen tomada, categorizada y compartida. La cuestión es, una vez más, la del iconismo, es decir el paso de la concepción de icono como signo definido por su relación de semejanza con la realidad del mundo exterior, al icono como ilusión referencial, en oposición tanto al concepto de índice (caracterizado por una relación de contigüidad natural) como al de símbolo (que se fundamenta en la simple convención social). Este paso es muy importante para una investigación semiótica del fenómeno porque permite desmontar la estrategia de la ilusión referencial y así analizar los procesos (estructuras semiótico-narrativas y estructuras discursivas) que están en la base de la construcción de una identidad mediática y de las relativas estrategias 
de persuasión del público. Hemos aclarado antes la importancia de la narración como motor central de los procesos comunicativos: la necesidad de contar, el deseo de escuchar historias. Con el final de las "grandes narraciones" nuestra época postmoderna y estetizante no ofrece ya una épica en la cual reconocer héroes, enemigos, valores e ideales, sino un pastiche estetizante, una procesión interminable de simulacros (Baudrillard) donde la vida está contada a través de postales: pequeños momentos cool puestos en un marco cuadrado. Todo esto es Instagram, la atomización glamour de nuestras vidas.

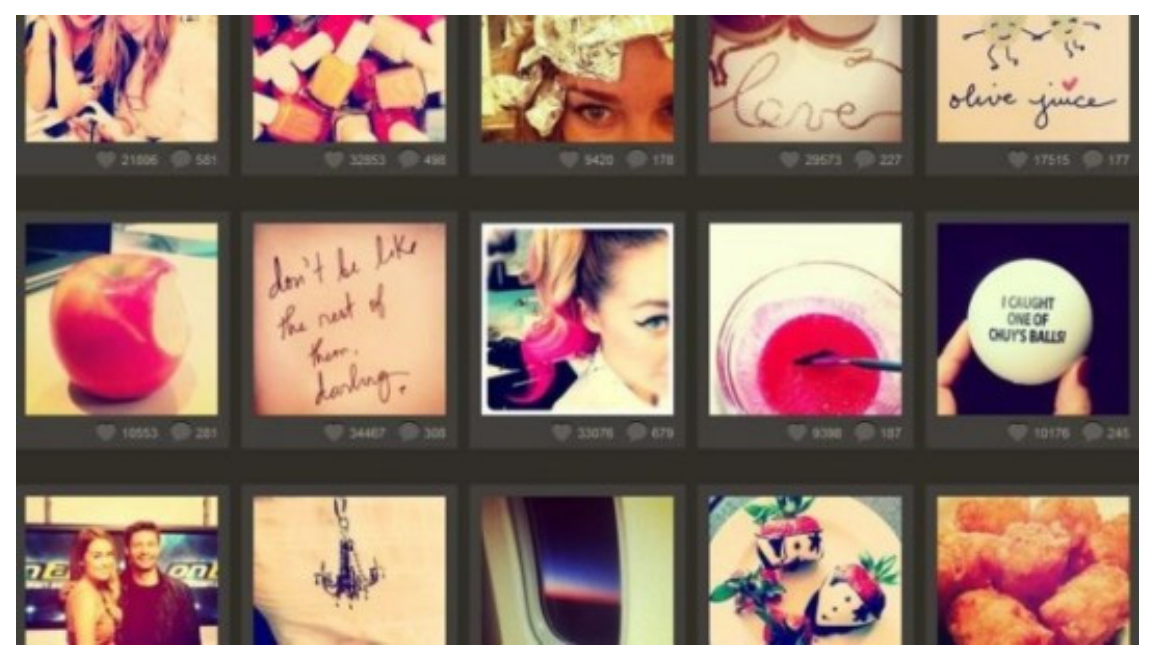

Fig. 7. Tomas de Instagram.

Instagram actúa en planos diferentes: la facilidad de uso, la creatividad, la idea de una competencia artística (la transformación de la imagen a través de determinados efectos y filtros) además de un plano socio-psicológico: la dimensión comunitaria (los contenidos son el resultado de la interacción entre una comunidad de usuarios con papel activo en el proceso de creación y de comentario/compartición). Susan Sontag fue profética al afirmar que "la fotografía se ha convertido en una de los principales herramientas para probar algo, para dar una semejanza de participación6". La siguió Roland Barthes, que en 1980 escribió: "en la era de la fotografía asistimos a una explosión de lo privado en lo público, o mejor a la creación de aquella nueva divisa social que es la publicización de lo privado ${ }^{6}$ ". Instagram es además un texto potentemente sincrético, porque no solo actúa a nivel visual, sino también a nivel verbal, a través de un sistema de \#hashtag (etiquetas que agrupan millones de imágenes en red), formando mosaicos potencialmente infinitos de ideas, paisajes y conceptos. Estamos ante un

5 S.Sontag, Sobre la fotografia, Barcelona: Edhasa, 1975.

6 Cit. en M.Bittanti, PRINTED MATTER: Fotografo dunque sono: estetica e ideologia di Instagram en Wired, Mayo 2011. http://www.mattscape.com/2011/05/instagram.html 
nuevo mecanismo de anclaje (el acompañamiento de un texto visual con un texto verbal) cuya función ya no es solo la de anclar el significado, seleccionando el sentido o los sentidos correctos de la imagen, sino también la de elegir aquellos significados que reciben la mayor visibilidad, es decir, los tags más populares. La popularidad ha superado a la corrección del mensaje y la construcción del sentido emerge cada vez más de una dimensión comunitaria y colectiva. Instagram, en definitiva, funciona porque ha entendido las macrotendencias de la sociedad postmoderna y mediática: por un lado la hiperexposición, la necesidad de una mise en scène y de un make up de lo real y, por otro, la búsqueda de la intimidad y afectividad obtenida gracias a determinadas herramientas retóricas: metonimias visuales, encuadres que ayudan a reconstruir el contexto perdido y a convocar los cotextos de la memoria del usuario. Además de todo esto actúa la potencia de la nostalgia: de lo real al efecto de realidad. La toma fotográfica es relativizada por el abundante surtido de filtros, marcos y desenfoques a disposición del usuario, un surtido que convoca aquella pátina del tiempo que vuelve así, con nuevas formas, a ocupar el centro del debate estético acerca del valor del arte. La nuestra es una época extraña: hipertecnológica y al mismo tiempo nostálgica: el formato de Instagram es cuadrado, en un claro homenaje a Polaroid, al sentido de intimidad imprecisa y desenfocada que parece ser la materia inconsistente del recuerdo. Efecto realidad y efecto retro en este caso parecen coincidir.
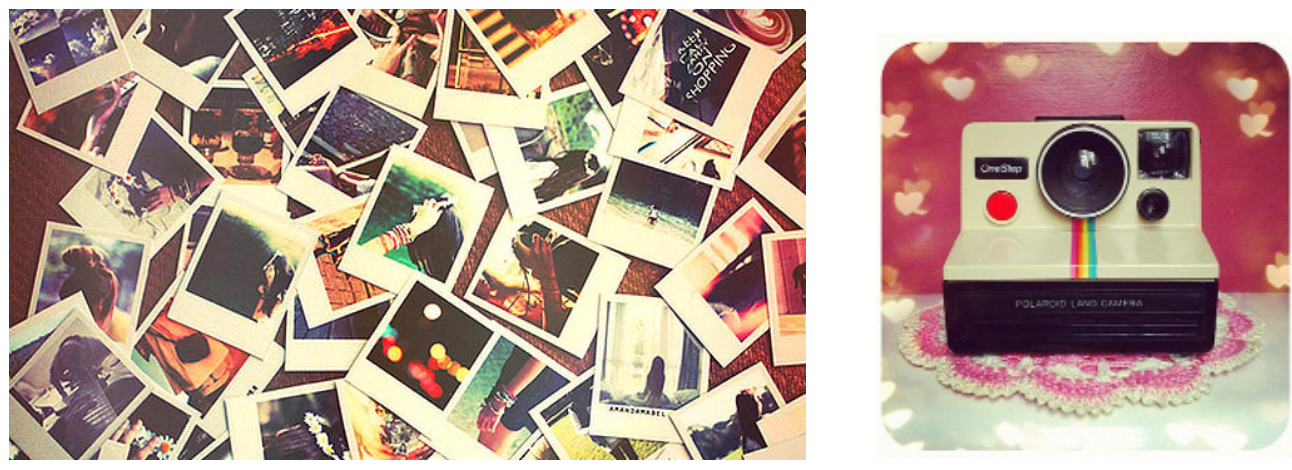

Fig. 8. La Polaroid.

El tiempo es sin duda un componente fundamental en este proceso persuasivo y nostálgico que actúa en dos momentos: la historia por una lado y el presente por el otro. El presente es el tiempo en el que queremos ejercer nuestro poder de productores de imágenes, a través de la notoriedad y de la cobertura mediática; la historia es el tiempo pasado del que tenemos que obtener la legitimación, usando la memoria colectiva y por ende el reconocimiento legitimante de una cierta resonancia emocional. 


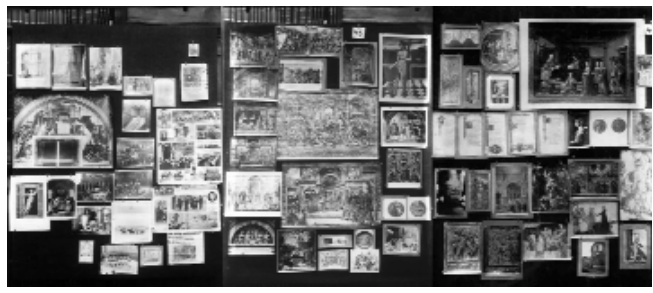

Fig. 9. Atlas Mnemosyne de Aby Warburg.

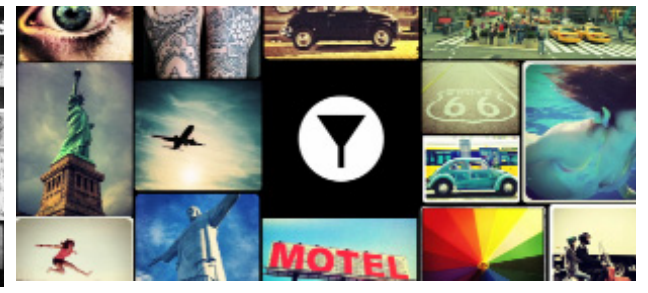

Fig. 10. Un "mosaico" de Instagram.

La celebrity como construcción mediática neo-icónica tiene que formar parte, y en muchos casos hasta promover, esta continua oscilación entre la fascinación del pasado y el adelanto de tendencias futuras, y siempre estará atenta a introducir las señales, los indicios de su propia pertenencia a una historia, a aquella historia que pretende superar, precisamente en virtud de su novedad. La estrategia del divismo moderno parece ser el mix de las décadas, la combinación de estilemas y figuras del pasado, reutilizados al fin de construir un áurea personal. Como consecuencia, la eficacia del divismo contemporáneo a través de Instagram depende de dos macro fuerzas: la iconográfica y la narrativa. La primera conlleva la construcción de una fisicidad y de una imagen capaces - gracias a elementos figurativos, gestuales, posturales y simbólicos - de remitir a una idea de divismo depositada en la memoria colectiva. La segunda actúa insertando en su propia historia los elementos de un cambio narrativo: pruebas, sanciones y glorificaciones de un mito que se construye contextualmente. El éxito de una iconografía depende, según esta misma estrategia, de la actualización de los modelos iconográficos y estilemas visuales del pasado: una migración temática de ascendencia warburgiana que considera el arquetipo como algo permanente y, al mismo tiempo, performante, que sin embargo conserva unos rasgos característicos que le garantizan una reconocibilidad propia...

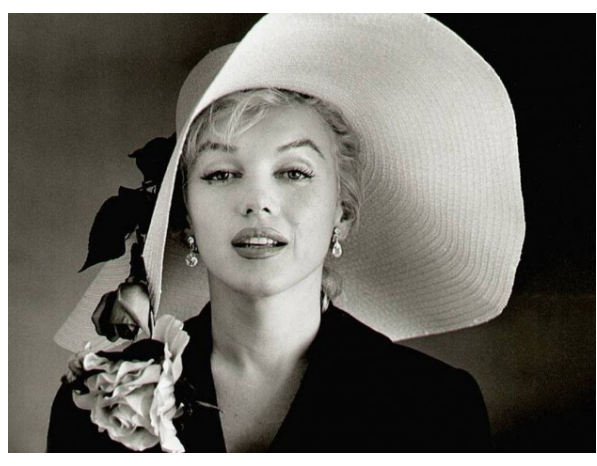

Fig. 11. Marylin Monroe.

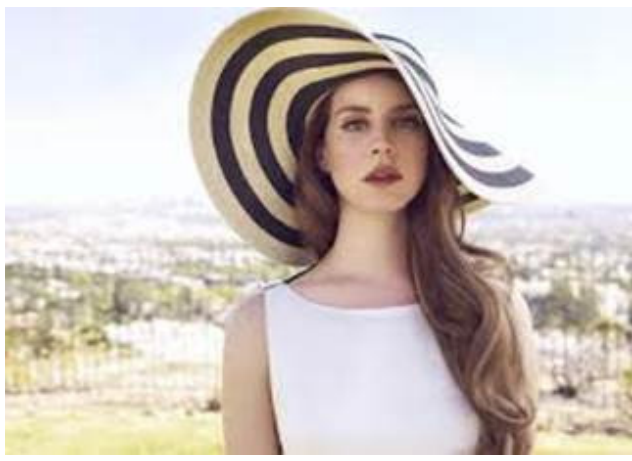

Fig. 12. Lana Del Rey. 
En este punto las dos fuerzas se funden: el éxito reside en la capacidad de insertar en la enunciación visual referencias de débrayage enunciativo, detalles muy cuidados de un contexto que el espectador tendrá que reconstruir despertando su fantasía narrativa. El espectador acabará reconstruyendo inconscientemente un antes y un después, usando todas las referencias cotextuales de las que dispone para completar el sentido de la imagen. En el caso de Lana Del Rey es evidente la construcción de una iconografía divística relacionada con el imaginario de perfección estética y de dramaticidad narrativa propias de los años sesenta estadounidenses, encarnados en la frágil sensualidad de Marilyn Monroe. Un débrayage que instala en el discurso enunciado un espacio "otro".

En conclusión, la construcción de un icono mediático contemporáneo está caracterizada por un proceso de planificación y por un calculado equilibrio entre imagen y narración, opacidad y transparencia, proximidad y distancia, gestionados a través de un atento uso de los filtros de la realidad, y para conseguirla será fundamental la más completa complicidad entre la persona y la máscara, la cual podría acabar ahogando el rostro humano que la hospeda.

\section{BIBLIOGRAFÍA}

BARILli, Renato (1974), Tra Presenza e assenza. Due modelli culturali in conflitto, Bompiani, Milán.

BARTHES, Roland (1957), Mitologías, Biblioteca Nueva, Madrid 2012.

BAUDRILLARD, Jean (1995), El crimen perfecto, Anagrama, Barcelona 1996

Bloom, Ina (2007), Art, Sociality and Media Culture, Sternberg Press, Berlín.

Bonnefoy, Yves (2005) La civiltà delle immagini, Donzelli, Roma

CodelupPI,Vanni (2007), La vetrinizzazione sociale. Il processo di spettacolarizzazione degli individui e della società, Bollati Boringhieri, Turín .

Dyer, Richard (1993), Dell'immagine. Saggi sulla rappresentazione, Kaplan, Turín 2004.

- (1979), Stars, British Film Commission, Londres.

JANDELLI, Cristina (2007), Breve storia del divismo cinematografico, Marsilio, Venezia.

LANDOWSKI, Eric (1989), La sociedad figurada: ensayos de sociosemiótica, Fondo de Cultura Económica, México 1993.

MAFFESSOLI, Michel (2002), "Vitalismo e empatia: lusso postmoderno", en Agalma, n 2, 91-95. MARIN, Louis (1993), De la représentation, Seuil, París.

MoRIN, Edgar (1962), El espiritu del tiempo, Taurus, Madrid 1966.

MuZZARelli, Federica (2013) Moderne icone di moda. La costruzione fotografica del mito, Einaudi,Turín.

PinotTi, Andrea; Somaini, Antonio (2009), Teorie dell'immagine. Il dibattito contemporaneo Raffaello Cortina Editore, Milán.

SfardinI, Anna (2009), Reality Tv. Pubblici, fan, protagonisti, performer, Unicopli, Milán. SonTAG, Susan (1973), Sobre la fotografía, Edhasa, Barcelona 1981. 


\title{
RESUMEN
}

La semiosfera mediática contemporánea se perfila como una explosión de aquel iconic turn que nació hace veinte años. El análisis del fenómeno del divismo nos permite estudiar a la celebrity como construcción mediática que forma parte, y en muchos casos hasta promueve, una continua oscilación entre la fascinación del pasado y el adelanto de tendencias futuras, y que está caracterizada por un proceso de planificación y por un calculado equilibrio entre imagen y narración, opacidad y transparencia, proximidad y distancia, gestionados a través de un atento uso de los filtros de la realidad.

Palabras clave: iconos, divos, celebrities, narración, imagen.

\section{Stardom in the Age of \#Instagram}

\begin{abstract}
The contemporary media semiosphere emerges as an explosion of that iconic turn issued twenty years ago. The analysis of the phenomenon of nowadays celebrities allows us to observe the continuous oscillation between fascination of the past and advancement towards future trends. The new celebrities are characterized with a planified process and a calculated balance between image and narration, opacity and transparency, proximity and distance, managed through an attentive use of the filters of reality.
\end{abstract}

Keywords: icons, divas, celebrities, narration, image.

\section{RÉSUMÉ}

Le semiosphère médiatique contemporaine émerge comme une explosion de ce tour iconique emblématique que naît vingt années avant .Le analyse du phénomène de l'ère neo-icónique faite dans l'étude nous permet de construire la célébrité médiatique comme néo-iconique, et de observer comment dans de nombreux cas elle sert à promouvoir une oscillation permanente entre la fascination du passé et l'avancement des tendances futures, et se caractérise par un processus de planification et un équilibre calculé entre l'image et de la narration, l'opacité et la transparence, la proximité et la distance, c' est à dire par l'utilisation attentive des filtres de la réalité.

Mots-clé: icônes, divas, célébrités, ére néo-iconique. 